\title{
Explaining the experiences, challenges and adaptation strategies of nurses in caring for patients with COVID-19: A qualitative study in Iran
}

\section{Seyed Fahim Irandoost}

Urmia University of Medical Sciences

Javad Yoosefi Lebni ( $\nabla$ j.yousefi28@yahoo.com )

Iran University of Medical Sciences

Hossein Safari

Iran University of Medical Sciences

Farhad Khoram

Islamic Azad University

\section{Sina Ahmadi}

University of Social Welfare and Rehabilitation Sciences

\section{Goli Soofizad}

Shahid Beheshti University of Medical Sciences

Farbod Ebadi Fard Azar

Iran University of Medical Sciences

\section{Research Article}

Keywords: COVID-19, Coronavirus, Experiences, Challenges, Adaptation Strategies, Nurses

Posted Date: October 30th, 2020

DOl: https://doi.org/10.21203/rs.3.rs-100575/v1

License: (9) This work is licensed under a Creative Commons Attribution 4.0 International License. Read Full License 


\section{Abstract}

Background: Nurses as the main human resource in coping with COVID-19 face many challenges and problems. Therefore, the present study aimed to explain the experiences, challenges, and adaptation strategies of nurses in taking care of patients with COVID-19 with a qualitative approach.

Methods: The present study was conducted with a qualitative conventional content analysis approach among 30 nurses working in wards for COVID-19 patients, in Tehran hospitals. Access to participants and data collection was done through purposive sampling, snowball sampling and semi-structured interviews. Data were analyzed using qualitative content analysis (conventional) and MAXQDA-18 software. Guba and Lincoln criteria were observed to evaluate the quality of research results.

Results: From data analysis, 2 main categories and 16 subcategories were obtained, including (1) experiences and challenges (lack of protective equipment, high work pressure, marginalized physical health, problems related to the use of protective equipment, getting excluded, lack of supportive work environment, problems related to patients, psychological problems, fear, marginalized personal and family life and the challenge of communication with patients' families) (2) Strategies for adapting to working conditions (performing religious-spiritual activities, creating an empathetic atmosphere in the workplace, spiritualizing their work , trying to convince the family and gain their support, strengthening sense of self-worth and responsibility).

Conclusion: The working conditions for nurses can be improved through providing adequate protective equipment, providing a suitable work environment and more social and financial support, more attention to the physical and mental health of nurses and considering appropriate mechanisms for nurses to communicate with their families and patients' families.

\section{Background}

COVID-19 is an acute respiratory disease of the coronavirus family that broke out in December 2019 in Wuhan, China [1]. Although the world has experienced infectious diseases in the past, the outbreak of COVID-19 as a new infectious disease has severely challenged the public health systems of different countries [2, 3]. The disease has spread to most countries of the world, so that by September 4, 2020, the total number of people infected with COVID-19 was $26,668,817$ and the number of deaths was 876,319 . The United States has the highest COVID-19 mortality rate at 191,600. Iran is one of the countries with the highest level of involvement with COVID-19 with 382,772 people infected and 22,044 deaths [4]. Although the death rate from the virus varies, the World Health Organization reports a mortality rate of $3.5 \%$ [5].

In the case of infectious diseases, health workers always play the most important role in the treatment of patients, and in this way, their health is endangered or they may even lose their lives. One-third of all SARS deaths in 2003 were reported to be attributed to health care professionals and staff [6]. At the same time, nurses experience physical and psychological stress and feel isolated and helpless in the face of health threats posed by such public health emergencies [7]. Previous studies have shown that when 
nurses are in close contact with patients with emerging infectious diseases such as SARS, Ebola, and the flu, they suffer from loneliness, anxiety, fear, fatigue, sleep disorders, and other physical and mental health problems [8-10]. In one study, the rates of depression, insomnia, and stress in nurses involved in the treatment of patients with SARS were $38.5,37$ and $33 \%$, respectively [11]. In studies conducted by Lee et al, 2018; Maunder et al, 2003 Health care providers caring for patients during the outbreak of Severe Acute Respiratory Syndrome (SARS) and Middle East Respiratory Syndrome (MERS) were under the pressures of high risk of infection, stigma, lack of nursing staff, and uncertainty and nurses needed comprehensive support during and after the outbreak $[12,13]$.

With the outbreak of COVID-19 virus in the world, the health of health workers, especially nurses, as the main human resource in fighting against this disease was endangered, leading to the death of many of them [2]. In China, 1,716 health personnel got COVID-19, and five of them died [14]. In Italy, nurses also had the highest number of health workers with the disease [15]. Liu, Yang et al, 2020 also showed that health care providers who treat patients with COVID-19 are more likely to have mental health problems such as anxiety, depression, insomnia, and stress [16]. Also, Liu, Luo et al, 2020 in their qualitative research in China showed that in the period of COVID-19 outbreak, health care providers were confronted with problems such as feeling responsible for reducing patient suffering, working in a completely new environment, burnout due to heavy burden of work and protective equipment, fear of getting infected and infecting others, feeling unable to handle patients' conditions and managing relationships in these stressful situations [17]. Sun, shi et al, 2020 in a study among nurses caring for COVID-19 patients showed that nurses experienced negative emotions in the early stages, including fatigue, discomfort and helplessness due to hard work, fear and anxiety and worry; for adaptation to existing conditions they have used personal adjustment styles including psychological adjustment, altruistic practices, team support, and rational cognition [2].

Given that health care providers are vital resources and manpower for any country and their health and safety are essential not only for continuous and safe care of patients but also to control any outbreak of disease, the importance of this study is clear. On the other hand, to effectively support health care providers and nurses and provide a safe environment for them to perform their job duties in critical periods, especially the outbreak of COVID-19, it is essential to gain new insights by recognizing their experiences and challenges in work environments and their strategies for adaptation to this situation. This will be possible through a qualitative approach, and although qualitative research has been conducted to examine the experiences and challenges of health staff and nurses in relation to COVID-19 in the world, but a study that has examined these experiences from a qualitative perspective in Iran has not been found. Therefore, the present study aimed to explain the experiences, challenges, and adaptation strategies of nurses caring for patients with COVID-19 with a qualitative approach.

\section{Methods}

\section{Design and Participants}


This qualitative study was conducted with a qualitative conventional content analysis approach [18-20] among nurses working in wards for COVID-19 patients in Milad, Haft Tir, Yaftabad, Lolagar, Imam Khomeini, and Masih Daneshvari hospitals in Tehran. Inclusion criteria included working in the ward for COVID-19 patients, being physically healthy and willingness to participate in the study.

\section{Data collection}

In this study, first purposive sampling and then snowball sampling were used. After receiving the code of ethics from Iran University of Medical Sciences and the necessary permissions for research, the researcher first received the contact numbers and addresses of 5 nurses who worked in the COVID-19 ward from friends who worked in the hospital, and then the rest of the participants were introduced by these nurses. During a telephone call, the researcher fully explained the purpose of the research and the process of conducting it to the participants and asked them for the time and place of the interview.

Data were collected through semi-structured interviews from April 1 to May 4, 2020. Most of the interviews (20 cases) were conducted face to face with full observance of health tips and the rest of the interviews were conducted by telephone. Most of the interviews ( 21 cases) were conducted by the first author of the article, who is a doctor of health education and health promotion and a specialist in qualitative research. In cases where female nurses requested a female interviewer, a skilled researcher familiar with qualitative research was used. In-person interviews were conducted in places such as the participants' homes and their break rooms in the hospital. All interviews were recorded with the permission of the participants, and during the interviews, notes were taken as needed.

At the beginning of the interview, in order to create a friendly atmosphere, the researcher gave a brief description of his / her personal and educational information, then explained the necessity of the research and how to conduct and report it. After receiving the written consent of the participants in the face-to-face interviews and the verbal consent in the telephone interviews, the research began with a few demographic questions. The interview questions were then asked based on a guide to interview questions that had already been compiled with the cooperation of all the authors of the article (Table 1). All guiding questions were asked of the participants. Of course, the order of the questions was not the same for all of them and in some cases it changed according to the answers of the participants. The average interview time was 50 minutes. The minimum and maximum interview times were 40 and 70 minutes, respectively. Data collection was completed with the participation of 30 nurses and with theoretical saturation criterion which is the main criterion of sampling in qualitative research. In fact, after the codes obtained from the interviews were repeated and no longer added a new concept to the research, the researchers found that they had reached theoretical saturation. However, for more certainty, 5 more interviews were conducted after the codes were repeated. Nothing new was found.

\section{Data analysis}

MAXQDA-2018 software was used to manage the data. Data analysis was performed by the first, second and corresponding authors of the article. It should be noted that the data analysis process was sent to all 
authors and the categories and subcategories were named after summarizing the opinions of all of them. In data analysis, the proposed method of Graneheim and Lundman, which includes 5 steps, was followed [21]. In the first step, the researchers listened to the recorded files of all the interviews several times and typed them. In the second step, the text of the interviews was reviewed several times by the researchers to reach a general understanding of the text. Then, in the third step, the texts were read carefully line by line and the initial codes were extracted. In the fourth step, the researchers put all the codes that were similar in concept and content into one category. In the final step, the data were placed in the main classifications, which were more general and conceptual, and the themes were extracted.

\section{Ethical Considerations}

To observe ethical considerations, in the first step, two specialist physicians working in the field of COVID19 were consulted so that the interviews would be conducted in a way that posed no threat to the health of the participant and the researcher. Therefore, all the health issues were observed in the interview process. Written consent was obtained from the participants in the face-to-face interview and verbal consent was obtained from the participants in the telephone interview. Participants were reassured that their names or identities would not be published in the results. They were also told that they had no obligation to participate in the study and that they could withdraw from the interview at any time.

\section{Trustworthiness}

To ensure the trustworthiness and reliability of the data, the four criteria of Guba and Lincoln were observed [22, 23]. Also, 32 items of the qualitative research report of Tong et al, 2007 were observed [24]. In order to obtain credibility, items such as selecting participants with maximum variety and feedback on the results and confirmation were done. In order to gain confirmability, parts of the interview text along with all the extracted codes, categories, and sub-categories were evaluated and approved by 5 observers who were outside the research team and familiar with the qualitative method. To achieve dependability, the participation, and use of the opinions of all authors in the analysis and coding was considered. In order to obtain the transferability criterion, some items were observed, including frequent use of direct quotations of the participants in the research, a complete description of the research steps and how to do them, and providing the research results for 5 nurses out of the research who had similar conditions as the participants had and getting their approval.

\section{Results}

A total of 30 nurses participated in this study, whose demographic information is shown in Table 2. After analyzing the data, 120 primary codes, 16 subcategories, and 2 main categories were extracted (Table 3 ), which are mentioned along with quotations and explanations.

\section{1-Experiences and challenges}


With the outbreak of COVID-19 in Iran and the hospitalization of its patients in hospitals, the personal and work life of nurses who are the most important medical personnel in fighting against COVID-19 undergo changes such as lack of protective equipment, high work pressure, marginalized physical health, problems related to the use of protective equipment, getting excluded ion, lack of supportive work environment, problems related to patients, psychological problems, fear, marginalized personal and family life and the challenge of communication with patients' families.

Lack of protective equipment. One of the most important problems that nurses had in facing with COVID19 disease from the very beginning of the disease was the lack of protective equipment such as gloves, high quality masks, face shields, disinfectant solution, and isolation clothes. This was a concern for many nurses and endangered their health.

"From the very first days we did not have isolation clothes. Many times we had to have contact with patients who were suspected of having COVID-19 without isolation clothes. Now the situation has improved, but sometimes we have to economize a lot." (P 4)

"Two pairs of gloves a day was too little for us." (p. 6)

"In the beginning, when we had a shortage, they gave us a simple mask which was of very low quality." (p. 11)

"In the early days, we had little hygienic products, we had to save a lot, and our lives were in danger." (p. 3)

High work pressure. With the increase of prevalence of COVID-19, the number of hospitalized patients increased day by day, and many hospitals faced a shortage of nurses, which led to longer hours of work for nurses. Also, since COVID-19 patients did not have any companions, most of their work was done by nurses, and due to their physical condition, nurses had to check them more than other patients. These issues put nurses under a lot of work pressure.

"We have been so busy. The number of patients is increasing and we have to work harder." (p. 23)

"The COVID-19 patient has a lot more work to do. We have to pay attention to and check them all the time because they don't have any companions." ( $p$ 2)

"Because the number of our staff has decreased and the number of patients has increased, we have to work much harder than before." (p. 17)

"We have a lot of work, we do not have a rest, I am getting tired, I am getting less" ( $p$ 4)

Marginalized physical health. With the increase of work pressure and psychological problems that occurred to nurses in some cases, their health was affected and they faced problems such as fatigue, headache, muscle fatigue, weakness and lethargy. Also, due to high work pressure and work stress, their sleep quality was low and in terms of nutrition, they faced digestive problems, disrupted eating hours, and 
eating habits. Most female nurses also reported that they had many problems during menstruation because they did not get enough rest.

"Sometimes I get so tired that I'm to fall asleep standing up." (p. 19)

"I do not have enough rest and sleep so I have a headache; I have pain in whole body." ( $p 27)$

"Sometimes we get so busy we can't even eat lunch and dinner, recently my stomach has a problem." ( $p$. 16)

"I had menstruation last week; I went to the brink of death. I got very annoyed; I have never gotten bothered like this in my life by menstruation." (p. 5)

Problems related to the use of protective equipment. Most of the nurses stated that it was difficult for them to use protective equipment and it caused them many problems such as facial ulcers, shortness of breath, heat, sweating, body burns, itching and leg wounds. Due to the transmission COVID-19, nurses were forced to pay more attention to health issues and work for hours with protective equipment to avoid getting the disease. This made their work even harder.

"When I wear isolation clothes, I get very hot so I sweat a lot and my skin burns." (p. 12)

"Since I have been wearing these clothes, my skin has become sensitive and it itches all the time. I am very bothered." (p. 14)

"I get short of breath when I use shields, masks, etc. I often feel suffocated" (p. 21)

Getting excluded. Most nurses reported being neglected outside the hospital by friends, neighbors, and even family, and many people cut contact with them. Because COVID-19 is transmitted in a variety of ways, nurses who have contact with patients are more at risk of getting the disease. This makes people afraid of nurses. Also, since it is possible to carry the disease displaying no symptoms, people are more afraid of nurses and this leads to their getting excluded in society and even in the family.

"Most of our relatives don't greet me warmly anymore. They fear I go to their house. I met them several times outside, but they did not even say hello." (p. 26)

"Our neighbor's wife told my mother "Tell your daughter not to come home and stay in the hospital, otherwise we, the residents of the building, will have to evict you from the building."' ( $p .4)$

"My brother-in-law no longer lets my sister and her children come to our house for fear that I might take COVID-19. I am very upset with their behavior" (p. 8)

"People behave badly with us outside when they find out that we are nurses. I once took a taxi and said I wanted to go to the hospital. When he found out that I was a nurse and I work in the COVID-19 ward, he 
refused to take me to the destination and made me get out of the car. His behavior bothered me for a couple of days. "( $p .29)$

"My husband always insists that I don't go to work anymore, he says "you will take COVID-19, we will be miserable", but I can't, my conscience doesn't let me do such a thing." (p. 14)

"One of the biggest problems for us, nurses working in the COVID-19 ward, is that many of our families do not support us when we really need them in this situation. A friend of mine said his father told her "I'll give you twice the money the hospital gives you if you don't go to work"."( $p 20)$

Lack of supportive work environment. Most nurses were dissatisfied with the quality of services provided by the hospital, stating that they had problems in the workplace such as not having a suitable place to rest, crowded break rooms, lack of motivational stimuli such as material rewards, worries about dismissal, lack of psychological counseling to cope with the stress related to COVID-19 and lack of adequate training in how to deal with COVID-19 patients.

"We all have to stay in the hospital, but we do not have a good place to rest at all. Sometimes it gets too crowded and it is not possible to take a rest." (p. 9)

"The officials praise us all the time but do nothing to make us happier and more hopeful. They did not provide us with any material rewards." (p. 3)

"We nurses have had the most stress and anxiety since COVID-19 came. Our days and nights have been messed up, but they have not provided us any counseling to calm down." (p. 12)

"During the early spread of COVID-19, I was very confused. I did not know exactly how to treat patients. I was afraid of them because we weren't trained for such a situation." (p. 28)

Problems related to patients. A number of nurses stated that they had been abused and bullied by COVID19 patients. They were also upset to see COVID-19 patients in poor condition. In addition, because COVID19 patients were unaccompanied, they felt lonely and homesick in the hospital, which made it difficult for them to cope with the hospital conditions and caused them to have tension with the nurses in some situations.

"Patients who had been hospitalized for a few days became very homesick and impatient, and we had to calm them all down." (p. 19)

"Some patients talked to us badly and insulted us." (p. 7)

"Some COVID-19 patients were tired of staying in the hospital. They were less tolerant and sometimes they fought with our colleagues." (p. 6).

Psychological problems. Most nurses stated that they were depressed due to the complex and difficult conditions that had arisen. Also, some of them had self-morbidities and constantly thought they had 
COVID-19. The grief of losing colleagues was another psychological problem of nurses. Some of them were upset and worried that they would see their co-worker died or had to stay home.

"I was much stronger early on, but now I'm losing my patience and tolerance and I think about negative things all the time. I feel I got depressed, I'm very impatient." (p. 18)

"For a short time, I have been thinking I got infected? I tested twice, which was negative. I even told my family what to do if something happened to me." (p. 1)

"I always think I'm sick. I was very careful, but I still think I'm sick. I check myself all the time. When I have a cough I get worried." (P. 23)

"A few days ago, one of our colleagues passed away. We were very upset. My mind is very busy with it." (p. 6)

"I am very upset to see that some of my colleagues are infected and being bothered." (p. 17)

Fear. Most participants stated that worry and fear sometimes disrupt their lives. Most of them had fears of being infected, carrying, and transmitting to their families, the continuation of the disease and the unknownness of the COVID-19 virus.

"All my worries and fears are that I will pass the disease on to my family, because my father has a kidney transplant and he lives with us." (p. 11)

"I am very afraid of catching COVID-19. When I see the condition of patients, I am more afraid, but I don't show it. Sometimes I tell my patients not to be afraid of COVID-19 while I myself really fear of it." ( $p$ 27)

"I am worried that this disease will continue. Life in these conditions has really become very difficult for us nurses. I feel that if it continues, we won't be able to tolerate." (p. 16)

"That they discover something new about this disease every day makes me even more frightened because I get sure that scientists know very little about this disease and that is why they cannot find a cure for it." (p. 2)

Marginalized personal and family life. As the number of COVID-19 patients in Iran increased, as well as the medical staff becoming ill and in need of rest, hospitals became understaffed and the remained nurses had to spend more time in the hospital. This made them no longer available to the family. On the other hand, because of the possibility of being a virus carrier, many nurses preferred to stay in the hospital even when they were off-duty and did not return home, which further alienated them from their families. Some other nurses, who had to stay in the hospital full time, fell behind on many personal life plans such as marriage and their children's birthday.

"Sometimes it takes more than a week for me to see my family." (p. 8) 
"I haven't seen my 6-month-old son; I really missed him." (p. 15)

"I could not attend my son's birthday. I was very upset. I was away from them when my family needed me more than ever. I feel I am not a good father for them." (p. 18)

"My husband and I were supposed to get married in April, but I was at work all the time and we couldn't have a celebration." (p. 30)

The challenge of communicating with patients' families. Because the families of COVID-19 patients could not be with them, they were constantly in contact with the nurses to know about their patients, and the nurses were sometimes forced to report bad news to the families, such as the death or deterioration of the patient's status. This had become a concern for most nurses, who stated that they had many problems with patients' families. Also, because the families were far away from their patient and could not see his condition closely, when they heard the news of their patient's death, they sometimes accused the nurses of not treating their patient properly. This also caused tensions between families and nurses.

"Sometimes when I had to tell the patient's family that the test was positive, I got very annoyed. I did not know how to tell them; people were very afraid of this disease." (p. 3)

"I have reported the death of the patient to the families 3 times so far. It's a very hard work, we feel ashamed that we could not do anything for them." (p. 10)

"When we report the death of a patient to the families, some of them accuse us of being shirkers, sometimes they even insult us." (p. 25)

"Some families found our phone number and called us. Sometimes they called so many times that we felt impatient and frustrated; they wanted to know about their patient's condition all the time." (p. 11).

"Some people who called us or whom we called were bothering us; they expected us to explain the whole treatment process to them, asking a lot of questions. Sometimes we had no way but to turn off our phones." (p. 22)

\section{2-Strategies for adapting to working conditions}

In the face of the existing situation, nurses took some actions to increase the tolerance threshold or adapt better to new conditions, such as performing religious-spiritual activities, creating an empathetic atmosphere in the workplace, spiritualizing their work, trying to convince the family and gain their support, strengthening sense of self-worth and responsibility.

Performing religious-spiritual activities. Some nurses stated that they resorted to religious and spiritual activities such as praying, saying their daily prayers, and listening to the Qur'an in order to strengthen their spirits and calm themselves. In fact, through approaching God, they tried to find more peace.

"When I am very tired, I try to say my prayers at a suitable time; I get rid of tiredness." (p. 28) 
"When I am under a lot of stress, I get a chance and listen to the Quran. Then I feel very calm; it makes me feel good." (p. 9)

"When I talk to God, I feel that He hears my words, I calm down. I ask him to save us from this disease." ( $p$ 12)

Creating an empathetic atmosphere in the workplace. Most nurses reported that during the outbreak of COVID-19 their work and emotional relationships at work changed for the better, and they liked and helped each other more than before. In fact, nurses could make the workplace more conducive by creating an empathetic atmosphere by creating emotional relationships with patients, strengthening relationships with other colleagues, forgiveness and devotion, helping colleagues, giving positive feedback to colleagues, talking more with colleagues, and providing an atmosphere for jokes and laughter.

"I try to talk more with patients. Honestly, both they and I calm down. Sometimes I listen to their heartache; they talk about their past and their memories." (p. 14)

"Since the COVID-19 patients were admitted to our ward, the colleagues have helped each other more because they know we are all in a difficult situation." (p. 9)

"I feel good to see my colleagues help me. I have recently started my work. When they encourage me I feel good." (P. 16)

"When we are less busy, we sit and talk with our colleagues. We are all like each other and understand each other well, so we feel very calm when we talk to each other." (p. 24)

"Sometimes I joke with patients, I take the rise out of them, they like it too. When I'm not there, they ask my colleagues about me. Sometimes I joke with my colleagues; this makes me less bothered." (p. 17)

"Sometimes when there is a lot of pressure on me, I talk to my colleagues and change our shifts. They used to not accept it so easily, but now everyone understands each other; a very good atmosphere has been created in the hospital. I wish it always stays the same, even when the disease is controlled." ( $p 5)$

Spiritualizing their work. In order to cope with the new conditions, some nurses tried to give their work a spiritual aspect by considering their work as jihad in the way of God, equating death due to COVID-19 with martyrdom, receiving rewards in the hereafter. Some nurses considered themselves Mujahideen for the sake of God and believed that if they were infected with COVID-19 and died in this way, they would go to heaven because they were martyred in the way of God. They also believed that if they died, they would have a great reward with God in the hereafter.

"I now really think I'm on the battlefield. I'm not afraid of death. I used to be very scared, but not now because I'm sure if I die I'Il go to heaven" (p. 11) 
"Our work is almost something like jihad in the way of God. Few people accept to work in these conditions, even if they are given a very high salary." (p. 8)

"When I think that I am fighting for God and if I die I am a martyr, my courage increases and I want to work more." (p 26)

"Despite the fact that I work many hours, I do not feel tired at all because I know that God sees everything and sees my troubles, and I am sure that one day he will reward me for this effort, whether it is in this world or the hereafter." (p. 14)

Trying to convince the family and gain their support. Some nurses stated that they had tried to gain the support of the family so that they could get help from them as a strong emotional resource. To convince the family and gain their support, they took measures such as explaining the necessity of being in the hospital, explaining the importance of nurses' work, observing health principles and comforting the family, showing working conditions to family members, and making phone and video calls to the family.

"It was very important to me that my family be behind me, so I talked to them from the beginning and told them that if we nurses were not, the situation would get worse and everyone might get infected." ( $p .13)$

"I promised my family that I would take care of myself as much as possible so that I would not get infected. In order to ease their mind, I sometimes make a video call with the clothes I wear to see that I respect them and make them feel better." (p. 3)

"I talked to my wife and explained the working conditions to her. Thank God my wife is reasonable. She accepted the conditions and supported me a lot during this period, unlike my other colleagues who often had problems with their families." (p. 18)

"I try to call my mom or dad at least once a day and talk to them, so they can relax when they are less afraid and support more" (p. 21)

Strengthening sense of self-worth and responsibility. The attention and support of the people and the media to the medical staff, especially nurses, in cyberspace, made nurses feel happy and satisfied, so that it strengthened their sense of self-worth and responsibility.

"I feel good when I see that everyone thanks us and thinks of us." (p. 1)

"When I see that everyone is supporting us nurses, I feel that my work is very valuable; I like my work more than before." (P. 27)

"I did not like my job very much before. Last year, I took the entrance exam to go to study medicine, but now I understand what an important job I have." (p. 15)

"I used to make excuses and liked not to go to work. When I came, I was very bored and only thought about when my work would end, but this is not the case now. My sense of responsibility for my work has 
increased." (p. 13)

"I try to think more about the positive aspects of my work and how valuable it is; this way I feel better about it and it gets easier for me to work." (p. 6)

\section{Discussion}

The present study identified the experiences, challenges, and adaptation strategies of nurses in caring for patients with COVID-19 with a qualitative approach. The results showed that nurses in caring for patients with COVID-19 experienced challenges such as work stress, getting excluded, psychological problems, fear and communication challenges, and used strategies such as spiritualizing their work, performing religious activities, creating an atmosphere of empathy in the workplace and strengthening their sense of self-worth and responsibility to adapt to these difficult situations.

One of the main challenges of nurses in the present study was the lack of protective equipment. Most previous research has reported that in many countries around the world, nurses, in addition to being responsible for coping with COVID-19, face a lack of protective equipment $[14,15,25]$. This problem has also been reported during outbreaks of diseases such as MERS, Ebola, SARS, and influenza [8, 26-28]. In fact, during the outbreak of epidemics, due to the increasing use of hygienic products and the unpreparedness of countries for such conditions, there are problems in accessing these materials.

Other challenges that nurses stated in this study are high work pressure and multiple responsibilities due to many work shifts, the increased number of patients, more visits to patients, and doing patients' work due to not having a companion. The results of several studies on the challenges of nurses during the spread of epidemics have presented similar findings [16, 29-31]. In this regard, it is noteworthy that dealing with infectious diseases brings special pressures and challenges for medical staff. Hospitalization of patients and the lack of a definitive and effective drug for the treatment of COVID-19 put the greatest pressure on nurses, because the needs and physical condition of patients must be regularly monitored by nurses and patients need physical and psychological help of nurses.

Problems related to the use of protective equipment were another challenge for nurses which are consistent with previous research [32]. Fernandez et al, 2020 also reported in their study that frequent wearing and taking off protective clothing and equipment puts psychological stress on nurses and causes them bother and fatigue [33]. In fact, nurses had to wear special clothes for many hours to maintain their health, which created many limitations and problems for them.

The marginalization of nurses' physical health during the care for patients with COVID-19 with features such as fatigue, headache, muscle fatigue, weakness, and lethargy, insomnia and digestive problems was another result of the study in line with the last two problems (above) of nurses. Nurses' work pressure during an epidemic can lead to many physical problems such as fatigue, insomnia, headaches and anorexia [34]. Liu and Aungsuroch, 2019 showed that nurses after wearing protective clothes, did not drink water in order not to go to the toilet to save this clothes. As a result, with longer working hours, this 
leads to stress, physical and mental fatigue and eventually job burnout [35]. While rest, adequate nutrition, and understanding the basic needs of health care workers, observing health protocols, and using protective equipment are effective in staff's health [36]. High work pressure, fatigue and physical conditions resulting from patient care, as well as physical difficulties due to the use of protective equipment for a long time, lead to a weakening of nurses' immune systems; this marginalizes their health. This situation will pose several challenges for the health system in the future, as a major part of the health care workforce is weakening and burning out.

Nurses spend long hours in hospitals and medical centers due to high work pressure, but according to the participants in this study, these work environments do not provide them with much material, counseling and training support. However, studies have shown that organizational support, including the availability of specialized psychiatric counseling in these difficult work situations, can be very helpful and a determining factor in reducing stress and anxiety of medical staff and affecting their sleep quality [32].

Getting excluded by relatives, friends, neighbors, and even family members was another problem raised by nurses. In a finding similar to our results, Kim, 2018 showed that South Koreans considered nurses to be carriers of the infection at the time of MERS outbreak and kept away from them [8]. Whereas nurses need to be in contact with family and friends to receive spiritual support [37]. The support of family and friends and their empathy is very important in improving the health and performance of medical staff and nurses [32]. Regarding the very sensitive situation of nurses during the time of caring for patients with COVID-19, their getting excluded by others and loss of social support add psychological problems to their work stress and exacerbates their problems.

Problems related to patients were another challenge of the nurses in the present study. In this regard, nurses may be abused and bullied by patients or seeing the discomfort and problems of patients and their serious condition may cause them bother. In a study conducted by Liu et al, 2020, nurses expressed grief over the sudden loss of patients 'lives and felt a severe inability to alleviate patients' suffering [17]. Marjanovic et al, 2007 also showed that anxiety and frustration caused by the inability to save people due to unknownness of the disease and lack of definitive treatment is one of the nurses' problems [38]. Nurses tend to help people maintain and recover health, but the current state of COVID-19 spread has led to the death tsunami [25], and burnout and frustration due to the inability to save people cause physical and emotional damage for nurses.

Psychological problems were another challenge for nurses in the present study, which may be due to issues such as the worry of getting the disease, the high work pressure, being distant from family, and inability to treat patients and seeing them die. Most studies of pandemic diseases have reported that nurses had mental health problems [12, 34, 39-43]. Yu et al, 2020 also reported the prevalence of high anxiety among nurses as a result of COVID-19 in their study [44]. Nurses face many psychological problems under normal circumstances, but in the COVID-19 period, due to the effects and consequences of this disease, this problem is exacerbated and it is necessary to give them special attention. 
Fear of getting COVID-19 and transmitting it to the family along with fear of unknownness and persistence of the virus was another challenge for nurses in the present study. The fact that more than $30 \%$ of deaths due to SARS were related to the death of healthcare professionals [6] justifies this fear. Numerous studies in line with our study mentioned challenges such as nurses' fear of getting the infection and transmitting it to family members [13, 45-49], fear and helplessness due to the outbreak of the disease $[7,8]$ and rapid change in recommendations and knowledge related to emerging and unknown diseases [50-52]. According to the results of the Cui et al, 2020 study, the most important predictor of anxiety and stress in nurses working in the COVID-19 ward was the fear of infecting family members [53]. COVID-19 has caused a great deal of fear among nurses due to its great unknownness and the ways of its transmission, so that most nurses are concerned that in addition to their own health, they also endanger the health of their family members.

One of the interesting findings of the present study was the marginalized personal and family life, especially for married nurses. Nurses go through difficult times during the outbreak of COVID-19, and in addition to homesickness for family members they also experience the pressure of having the roles of wife and mother. Quarantine conditions and the closure of schools and kindergartens add to these pressures. On the other hand, the spread of this pandemic in Iran was at the same time with the ancient New Year holiday of Nowruz, which the long-term presence of nurses at work marginalized even brief ceremonies that one could have with family members, and kept nurses away from personal life.

The challenge of communicating with patients' families, such as informing about the exacerbation of patient's condition or the patient's death, was one of the new and noticeable results in this study. Nurses were bothered to see the suffering of patients, and when they knew they could not do anything to cure them, they were bothered even more. However, some families accused the nurses of being shirkers because they had not seen the process of treating and caring for the patients closely, and this created a tension between them and the nurses.

Another interesting and new result in this study was that nurses used special strategies to overcome the challenges and reduce their problems. One of these strategies was to perform religious and spiritual activities such as praying and listening to the Qur'an and saying the daily prayers. In similar studies, nurses have used spiritual activities such as meditation, mindfulness, and deep breathing to cope with the stress of epidemics $[11,12,41]$. Adapting to the difficult conditions of caring for patients with COVID19 in Iran, a religious community that believes in religious teachings, can be facilitated by religious activities. These activities calm the person and raise the threshold for enduring difficult situations.

Spiritualizing their work was another interesting strategy that nurses used in this study to adoption with their new job conditions and is in line with the previous strategy. That is, nursing was considered not just a duty, but a sacred work with a reward in the hereafter. In other studies, the issue of "conscience" was mentioned as the strongest driving force for role-playing [54], which has transformed the nursing profession from a regular job and sanctified it [55]. Giving a spiritual and special place to their job facilitates the fulfillment of responsibilities and causes nurses adapt to new conditions. In many cases, 
this spirituality has been a key factor in performing professional duties, and people believe that if they sacrifice their lives to serve patients, they will be rewarded in another world, and this kind of belief in religious communities such as Iran is more common.

Creating an empathetic atmosphere at work was another strategy used by the nurses in the present study, which is confirmed by the results of other studies; When epidemics occur, nurses have more active altruism and stronger teamwork than ever before $[8,28]$. Nurses can change their cognitive logic according to an epidemic. They constantly adjust their cognitive assessment through their professional knowledge to promote mental balance, take the lead in altruism, and seek team support [10]. Thus, pandemic uncertainty among nurses can be controlled through effective collaboration in an atmosphere of mutual trust and respect [33]. This shows that it is important to pay attention to the psychological condition of nurses and in difficult situations, having psychological logic and the ability to adapt to adverse conditions, can all lead to better service to patients, and reduce the psychological and social harms of nurses.

Strengthening a sense of self-worth and responsibility was another strategy that helped nurses adoption with the harsh conditions of COVID-19 outbreaks. A sense of responsibility is created by professional ethics during the period of diseases outbreak. Encouraging nurses to take an active part in anti-epidemic tasks strengthens their professional identity and pride [51]. On the other hand, the results of previous studies show the psychological development of nurses during epidemic outbreaks $[11,28]$. At the same time, strengthening responsibility was effective in performing the job duties of the nurses in the present study. In China, the slogan "Everyone is responsible for the progress or downfall of their country" is evident in reinforcing nurses' sense of responsibility during the difficult times of COVID-19 [17]. In the study of Fernandez et al, 2020, nurses, despite feeling fear and vulnerability, had a strong sense of duty and responsibility towards patients and considered themselves obliged to serve [33].

The last strategy used by the nurses in the present study was to try to convince the family and gain their support. Mo et al, 2020 showed that social support is an important protective factor for psychological resilience that reduces mental stress and relieves psychological problems. Social support can also reduce the effect of employment stress on health [37]. In order to be able to receive social and spiritual support, nurses must be in contact with their family and friends and then they are able to fulfill their job responsibilities and at the same time enjoy social acceptance and not be excluded.

\section{Limitations and strengths}

This study is one of the few studies that examines the experiences and problems of nurses as well as their adaptation strategies in caring for patients with Quid 19 from their own perspective, which can provide useful information to hospital managers so that they can take steps to reduce their problems in order that nurses can work in better conditions. This study also had some limitations; This included scheduling the interview, which was one of the main limitations of the study, because nurses had difficulty in determining the time of the interview due to a lot of work shifts and lack of adequate rest, and the interview time changed many times with their opinion. Observing the health principles for the 
interview, such as keeping a safe distance and wearing a mask, in some cases made the voices of the respondents not loud during the recording of the interview, and the researchers asked the participants to speak louder. Another limitation was that some of the women participants tended to have female interviewers so that they could more easily share their experiences with the researcher, so the researchers used a trained female researcher who was familiar with the principles of interviewing and qualitative research.

\section{Conclusion}

The results showed that nurses in caring for patients with COVID-19 confront multiple and multi-aspect challenges such as work pressure, lack of protective equipment, getting excluded, psychological problems, fear, marginalized personal and family life, lack of supportive work environment, problems related to patients and relationships with their families; to cope with these emerging conditions and overcome these challenges, they used strategies such as performing religious activities and spiritualizing their work, trying to gain family support, creating an empathetic atmosphere at work, and strengthening their sense of self-worth and responsibility. Therefore, these challenges can be reduced by providing adequate protective equipment, providing a suitable work environment and more social and financial support, proper management of work shifts, more attention to the physical and mental health of nurses and considering appropriate mechanisms for nurses' communication with their families and patients' families. It is also possible to provide better conditions for nurses by reproducing and reinforcing the strategies used by them.

\section{Declarations}

\section{Ethics approval and consent to participate}

The study was provided ethical approval by the Iran University of Medical Sciences (IR.KUMS.REC.1399.501). Written consent was obtained from all participants.

\section{Consent to publish}

Not applicable.

\section{Competing interests}

The authors declare that they have no competing interests.

\section{Availability of data and materials}

The datasets used and/or analyzed during the current study are available from the corresponding author on reasonable request.

\section{Funding}


Not applicable.

\section{Authors' contributions}

All authors participated and approved the study design. JYL and SFI contributed in designing the study, GS, FKH and SA collected the data, and analyzed by SFI, JYL, and HS. The final report and article were written by SFI, JYL, SA and FEFA and all authors read and approved the final manuscript.

\section{Acknowledgments}

All participants in this study are appreciated.

\section{Author details}

${ }^{1}$ Department of Public Health, School of Health, Urmia University of Medical Sciences, Urmia, Iran ${ }^{2}$ Health Promotion Research Center, Iran University of Medical Sciences, Tehran, Iran ${ }^{3} \mathrm{Health}$ Promotion Research Center, Iran University of Medical Sciences, Tehran, Iran ${ }^{4}$ Master of Clinical Psychology, Islamic Azad University, Kermanshah Branch, Kermanshah, Iran ${ }^{5}$ Department of Social Welfare Management, Social Welfare Management Research Centre, University of Social Welfare and Rehabilitation Sciences, Tehran, Iran ${ }^{6} \mathrm{PhD}$ Student, School of public Health and Safety, Shahid Beheshti University of Medical Sciences, Tehran, Iran ${ }^{7}$ Health Promotion Research Center, Iran University of Medical Sciences, Tehran, Iran

\section{Abbreviations}

Not applicable

\section{References}

1. Zhu N, Zhang D, Wang W, Li X, Yang B, Song J, et al. A novel coronavirus from patients with pneumonia in China, 2019. New England Journal of Medicine. 2020.

2. Sun $\mathrm{N}$, Shi $\mathrm{S}$, Jiao $\mathrm{D}$, Song $\mathrm{R}, \mathrm{Ma} \mathrm{L}$, Wang $\mathrm{H}$, et al. A qualitative study on the psychological experience of caregivers of COVID-19 patients. American Journal of Infection Control. 2020.

3. Yoosefı Lebni J, Abbas J, Moradi F, Salahshoor MR, Chaboksavar F, Irandoost SF, et al. How the COVID-19 pandemic effected economic, social, political, and cultural factors: A lesson from Iran. International Journal of Social Psychiatry. 2020:0020764020939984.

4. worldometers.info. https://www.worldometers.info/coronavirus/ 2020.

5. Organization WH. Coronavirus disease 2019 (COVID-19): situation report, 82. 2020.

6. Hung LS. The SARS epidemic in Hong Kong: what lessons have we learned? Journal of the Royal Society of Medicine. 2003;96(8):374-8.

7. O'Boyle C, Robertson C, Secor-Turner M. Nurses' beliefs about public health emergencies: fear of abandonment. American journal of infection control. 2006;34(6):351-7. 
8. Kim Y. Nurses' experiences of care for patients with Middle East respiratory syndrome-coronavirus in South Korea. American journal of infection control. 2018;46(7):781-7.

9. Khalid I, Khalid TJ, Qabajah MR, Barnard AG, Qushmaq IA. Healthcare workers emotions, perceived stressors and coping strategies during a MERS-CoV outbreak. Clinical medicine \& research. 2016;14(1):7-14.

10. Honey M, Wang WY. New Zealand nurses perceptions of caring for patients with influenza A (H1N1). Nursing in Critical Care. 2013;18(2):63-9.

11. Su T-P, Lien T-C, Yang C-Y, Su YL, Wang J-H, Tsai S-L, et al. Prevalence of psychiatric morbidity and psychological adaptation of the nurses in a structured SARS caring unit during outbreak: A prospective and periodic assessment study in Taiwan. Journal of Psychiatric Research. 2007;41(12):119-30.

12. Lee SM, Kang WS, Cho A-R, Kim T, Park JK. Psychological impact of the 2015 MERS outbreak on hospital workers and quarantined hemodialysis patients. Comprehensive psychiatry. 2018;87:123-7.

13. Maunder R, Hunter J, Vincent L, Bennett J, Peladeau N, Leszcz M, et al. The immediate psychological and occupational impact of the 2003 SARS outbreak in a teaching hospital. Cmaj. 2003;168(10):1245-51.

14. Sun P, Qie S, Liu Z, Ren J, Xi JJ. Clinical characteristics of 50466 patients with 2019-nCoV infection. medRxiv. 2020.

15. Nurses ICo. High proportion of healthcare workers with COVID-19 in Italy is a stark warning to the world: protecting nurses and their colleagues must be the number one priority. 2020.

16. Liu S, Yang L, Zhang C, Xiang Y-T, Liu Z, Hu S, et al. Online mental health services in China during the COVID-19 outbreak. The Lancet Psychiatry. 2020;7(4):e17-e8.

17. Liu Q, Luo D, Haase JE, Guo Q, Wang XQ, Liu S, et al. The experiences of health-care providers during the COVID-19 crisis in China: a qualitative study. The Lancet Global Health. 2020.

18. Speziale HS, Streubert HJ, Carpenter DR. Qualitative research in nursing: Advancing the humanistic imperative: Lippincott Williams \& Wilkins; 2011.

19. Irandoost SF, Taghdisi MH, Dehdari T, Bayangani B, Azadi NA. Obesity consequences from the people's perspective living in Kurdish regions of Iran: A qualitative content analysis. Journal of education and health promotion. 2019;8(159).

20. Gharehghani MAM, Irandoost SF, Soofizad G. Barriers to Condom Use Among Female Sex Workers in Tehran, Iran: A Qualitative Study. International Journal of Women's Health. 2020;12:681-9.

21. Graneheim UH, Lundman B. Qualitative content analysis in nursing research: concepts, procedures and measures to achieve trustworthiness. Nurse education today. 2004;24(2):105-12.

22. Lincoln YS, Lynham SA, Guba EG. Paradigmatic controversies, contradictions, and emerging confluences, revisited. The Sage handbook of qualitative research. 2011;4:97-128.

23. Lebni JY, Gharehghani MAM, Soofizad G, Irandoost SF. Challenges and opportunities confronting female-headed households in Iran: a qualitative study. BMC women's health. 2020;20(1):1-11. 
24. Tong A, Sainsbury P, Craig J. Consolidated criteria for reporting qualitative research (COREQ): a 32item checklist for interviews and focus groups. International journal for quality in health care. 2007;19(6):349-57.

25. Jackson D, Bradbury-Jones C, Baptiste D, Gelling L, Morin K, Neville S, et al. Life in the pandemic: Some reflections on nursing in the context of COVID-19. Journal of clinical nursing. 2020.

26. Kang HS, Son YD, Chae SM, Corte $C$. Working experiences of nurses during the Middle East respiratory syndrome outbreak. International journal of nursing practice. 2018;24(5):e12664.

27. Ives J, Greenfield S, Parry JM, Draper H, Gratus C, Petts JI, et al. Healthcare workers' attitudes to working during pandemic influenza: a qualitative study. BMC Public Health. 2009;9(1):1-13.

28. Shih F-J, Gau M-L, Kao C-C, Yang C-Y, Lin Y-S, Liao Y-C, et al. Dying and caring on the edge: Taiwan's surviving nurses' reflections on taking care of patients with severe acute respiratory syndrome. Applied Nursing Research. 2007;20(4):171-80.

29. Xuehua L, Li M, Fangiang M. Psychological stress of nurses in SARS wards. Chinese Mental Health Journal. 2003;17:526-7.

30. Xu M, Zhang Y. Psychological survey of the first-line clinical front-line support nurses to combat new coronavirus-infected pneumonia. Nursing Research of China. 2020;34(3):368-70.

31. Huang $\mathrm{L}$, rong Liu $\mathrm{H}$. Emotional responses and coping strategies of nurses and nursing college students during COVID-19 outbreak. MedRxiv. 2020.

32. Xiao H, Zhang Y, Kong D, Li S, Yang N. The effects of social support on sleep quality of medical staff treating patients with coronavirus disease 2019 (COVID-19) in January and February 2020 in China. Medical science monitor: international medical journal of experimental and clinical research. 2020;26:e923549-1.

33. Fernandez R, Lord H, Halcomb E, Moxham L, Middleton R, Alananzeh I, et al. Implications for COVID19: a systematic review of nurses' experiences of working in acute care hospital settings during a respiratory pandemic. International Journal of Nursing Studies. 2020:103637.

34. Johal SS. Psychosocial impacts of quarantine during disease outbreaks and interventions that may help to relieve strain. Journal of the New Zealand Medical Association. 2009;122(1296):47-52.

35. Liu Y, Aungsuroch Y. Work stress, perceived social support, self-efficacy and burnout among Chinese registered nurses. Journal of nursing management. 2019;27(7):1445-53.

36. Adams JG, Walls RM. Supporting the health care workforce during the COVID-19 global epidemic. Jama. 2020;323(15):1439-40.

37. Mo Y, Deng L, Zhang L, Lang Q, Liao C, Wang N, et al. Work stress among Chinese nurses to support Wuhan in fighting against COVID-19 epidemic. Journal of nursing management. 2020.

38. Marjanovic Z, Greenglass ER, Coffey S. The relevance of psychosocial variables and working conditions in predicting nurses' coping strategies during the SARS crisis: an online questionnaire survey. International journal of nursing studies. 2007;44(6):991-8. 
39. Nickell LA, Crighton EJ, Tracy CS, Al-Enazy H, Bolaji Y, Hanjrah S, et al. Psychosocial effects of SARS on hospital staff: survey of a large tertiary care institution. Cmaj. 2004;170(5):793-8.

40. Lam KK, Hung SYM. Perceptions of emergency nurses during the human swine influenza outbreak: A qualitative study. International emergency nursing. 2013;21(4):240-6.

41. Wong EL, Wong SY, Kung K, Cheung AW, Gao TT, Griffiths S. Will the community nurse continue to function during $\mathrm{H} 1 \mathrm{~N} 1$ influenza pandemic: a cross-sectional study of Hong Kong community nurses? BMC Health Services Research. 2010;10(1):107.

42. Tiwari A, Chan S, Wong A, Tai J, Cheng K, Chan J, et al. Severe acute respiratory syndrome (SARS) in Hong Kong: patients' experiences. Nursing outlook. 2003;51(5):212-9.

43. Smith MW, Smith PW, Kratochvil CJ, Schwedhelm S. The psychosocial challenges of caring for patients with Ebola virus disease. Health security. 2017;15(1):104-9.

44. Yu J, Song Y, Dong H, Su X, Zhang P. Factors associated with the general well-being of nurses in a tertiary Chinese hospital: A cross-sectional study. Journal of Nursing Management. 2020;28(3):5407.

45. Lee S-H, Juang Y-Y, Su Y-J, Lee H-L, Lin Y-H, Chao C-C. Facing SARS: psychological impacts on SARS team nurses and psychiatric services in a Taiwan general hospital. General hospital psychiatry. 2005;27(5):352-8.

46. Koh D, Lim MK, Chia SE, Ko SM, Qian F, Ng V, et al. Risk Perception and Impact of Severe Acute Respiratory Syndrome (SARS) on Work and Personal Lives of Healthcare Workers in Singapore What Can We Learn? Medical care. 2005:676-82.

47. Speroni KG, Seibert DJ, Mallinson RK. Nurses' perceptions on Ebola care in the United States, Part 2: A qualitative analysis. JONA: The Journal of Nursing Administration. 2015;45(11):544-50.

48. Corley A, Hammond NE, Fraser JF. The experiences of health care workers employed in an Australian intensive care unit during the H1N1 Influenza pandemic of 2009: a phenomenological study. International journal of nursing studies. 2010;47(5):577-85.

49. Bukhari EE, Temsah MH, Aleyadhy AA, Alrabiaa AA, Alhboob AA, Jamal AA, et al. Middle East respiratory syndrome coronavirus (MERS-CoV) outbreak perceptions of risk and stress evaluation in nurses. The Journal of Infection in Developing Countries. 2016;10(08):845-50.

50. Holroyd E, McNaught C. The SARS crisis: reflections of Hong Kong nurses. International nursing review. 2008;55(1):27-33.

51. Liu H, Liehr P. Instructive messages from Chinese nurses' stories of caring for SARS patients. Journal of clinical nursing. 2009;18(20):2880-7.

52. Lam SKK, Kwong EWY, Hung MSY, Chien WT. Emergency nurses' perceptions regarding the risks appraisal of the threat of the emerging infectious disease situation in emergency departments. International journal of qualitative studies on health and well-being. 2020;15(1):e1718468.

53. Cui S, Jiang Y, Shi Q, Zhang L, Kong D, Qian M, et al. Impact of COVID-19 on psychology of nurses working in the emergency and fever outpatient: A cross-sectional survey. 2020. 
54. Ellershaw J, Fullarton C, Rodwell J, Mcwilliams J. Conscientiousness, openness to experience and extraversion as predictors of nursing work performance: A facet-level analysis. Journal of nursing management. 2016;24(2):244-52.

55. Hewlett BL, Hewlett BS. Providing care and facing death: nursing during Ebola outbreaks in central Africa. Journal of Transcultural Nursing. 2005;16(4):289-97.

\section{Tables}

Table1 The guide for interview question

\begin{tabular}{|c|c|}
\hline No & Question \\
\hline 1 & What happened when the first patient with COVID-19 was admitted to your ward? \\
\hline 2 & $\begin{array}{l}\text { Has there been a change in your work duties these days while treating COVID-19 patients? } \\
\text { Explain. }\end{array}$ \\
\hline 3 & $\begin{array}{l}\text { Has there been a change in your mental or physical condition since treating COVID-19 patients? } \\
\text { Explain. }\end{array}$ \\
\hline 4 & What problems do you face most in nursing COVID-19 patients? \\
\hline 5 & $\begin{array}{l}\text { What is the reaction of those around you when they find out that you are in contact with a } \\
\text { COVID-19 patient? Explain. }\end{array}$ \\
\hline 6 & Are you satisfied with the services that your workplace provides you these days? Explain. \\
\hline 7 & What is the difference between caring for COVID-19 patients and other patients? Explain. \\
\hline 8 & What do you do to better put up with this situation? Explain. \\
\hline 9 & How do you adapt to this new situation (nursing the COVID-19 patients)? Explain. \\
\hline
\end{tabular}

Table 2 Demographic information of the participants 


\begin{tabular}{|lll|}
\hline variables & group & Frequency (\%) \\
\hline Age & Under 25 & $6(20)$ \\
\cline { 2 - 3 } & $25-40$ & $15(50)$ \\
\cline { 2 - 3 } Gender & Over 40 & $9(30)$ \\
\hline Marital status & male & $12(40)$ \\
\cline { 2 - 3 } & female & $18(60)$ \\
\hline Job experience & Under 5 & $12(40)$ \\
\cline { 2 - 3 } & m- 10 & $8(27)$ \\
\cline { 2 - 3 } & Over 10 & $10(33)$ \\
\hline
\end{tabular}

Table 3 Codes, subcategories, and categories extracted from data analysis 


\begin{tabular}{|c|c|c|}
\hline Categories & Subcategories & Codes \\
\hline \multirow[t]{11}{*}{$\begin{array}{l}\text { Experiences } \\
\text { and } \\
\text { challenges }\end{array}$} & $\begin{array}{l}\text { lack of } \\
\text { protective } \\
\text { equipment }\end{array}$ & $\begin{array}{l}\text { lack of protective equipment such as gloves, high quality masks, } \\
\text { face shields, disinfectant solution and isolation clothes }\end{array}$ \\
\hline & $\begin{array}{l}\text { high work } \\
\text { pressure }\end{array}$ & $\begin{array}{l}\text { Increasing work shifts, increasing number of patients, more visits } \\
\text { to patients due to too many drugs and giving different serums, } \\
\text { doing patients' work due to not having a companion }\end{array}$ \\
\hline & $\begin{array}{l}\text { Marginalized } \\
\text { physical health }\end{array}$ & $\begin{array}{l}\text { fatigue, headache, muscle fatigue, weakness and lethargy, } \\
\text { sleeplessness, low quality of sleep, digestive problems, disrupted } \\
\text { eating hours and eating habits, menstruation problems of female } \\
\text { nurses }\end{array}$ \\
\hline & $\begin{array}{l}\text { problems } \\
\text { related to the } \\
\text { use of } \\
\text { protective } \\
\text { equipment }\end{array}$ & $\begin{array}{l}\text { facial ulcers, shortness of breath, heat, sweating, body burns, } \\
\text { itching and leg wounds }\end{array}$ \\
\hline & $\begin{array}{l}\text { getting } \\
\text { excluded }\end{array}$ & $\begin{array}{l}\text { Relatives run away from dealing with nurses, inappropriate } \\
\text { behavior and avoidance of neighbors, inappropriate behavior of } \\
\text { others outside the workplace, inappropriate behavior of family } \\
\text { members }\end{array}$ \\
\hline & $\begin{array}{l}\text { lack of } \\
\text { supportive } \\
\text { work } \\
\text { environment }\end{array}$ & $\begin{array}{l}\text { not having a suitable place to rest, crowded break rooms, lack of } \\
\text { motivational stimuli such as material rewards, worries about } \\
\text { dismissal, lack of psychological counseling to cope with the stress } \\
\text { related to COVID-19 and lack of adequate training in how to deal } \\
\text { with COVID-19 patients }\end{array}$ \\
\hline & $\begin{array}{l}\text { problems } \\
\text { related to } \\
\text { patients }\end{array}$ & $\begin{array}{l}\text { Getting abused and bullied by patients, patients' boredom, patient } \\
\text { homesickness, seeing patients in bad condition }\end{array}$ \\
\hline & $\begin{array}{l}\text { psychological } \\
\text { problems }\end{array}$ & $\begin{array}{l}\text { Depression, self-morbidities, grief over losing a colleague due to } \\
\text { COVID-19 }\end{array}$ \\
\hline & fear & $\begin{array}{l}\text { fears of being infected, fear of carrying and transmitting to their } \\
\text { families, the continuation of the disease and the unknownness of } \\
\text { the COVID- } 19 \text { virus }\end{array}$ \\
\hline & $\begin{array}{l}\text { Marginalized } \\
\text { personal and } \\
\text { family life }\end{array}$ & $\begin{array}{l}\text { Disconnection with family, homesickness for family, reduction of } \\
\text { the role of mother or father in the family, being distant from the } \\
\text { family during Nowruz, not attending their child's birthday party, } \\
\text { disruption in life plans such as marriage, cancellation of family } \\
\text { travel plans }\end{array}$ \\
\hline & $\begin{array}{l}\text { the challenge } \\
\text { of } \\
\text { communication } \\
\text { with patients' } \\
\text { families }\end{array}$ & $\begin{array}{l}\text { Difficulty of informing families about positive test results, Difficulty } \\
\text { of informing families about their patient's death, Difficulty of } \\
\text { informing family about their patient's exacerbated condition, } \\
\text { Accusing the nurses of being shirkers by patient's family, too many } \\
\text { contacts by patient's family }\end{array}$ \\
\hline $\begin{array}{l}\text { Adaptation } \\
\text { strategies } \\
\text { for work } \\
\text { conditions }\end{array}$ & $\begin{array}{l}\text { performing } \\
\text { religious- } \\
\text { spiritual } \\
\text { activities }\end{array}$ & $\begin{array}{l}\text { Praying, saying daily prayers, listening to the Qur'an, saying } \\
\text { blessings to Prophet Muhammad[Salawaat], asking for help from } \\
\text { the Imams }\end{array}$ \\
\hline
\end{tabular}


creating an

empathetic

atmosphere in

the workplace creating emotional relationships with patients, strengthening relationships with other colleagues, forgiveness and devotion, helping colleagues, giving positive feedback to colleagues, talking more with colleagues, and providing an atmosphere for jokes and laughter

spiritualizing their work

considering their work as jihad in the way of God, equating death due to COVID-19 with martyrdom, receiving rewards in the hereafter

trying to convince the family and gain their support

explaining the necessity of being in the hospital, explaining the importance of nurses' work, observing health principles and comforting the family, showing working conditions to family members, and making phone and video calls to the family

strengthening sense of selfworth and responsibility
Feeling satisfied with strengthening their social image and status among people, satisfaction with people's gratitude, increasing their efforts to save people, increasing interest in their work and profession, taking responsibility for people's health 